\title{
ENTRE A COOPERAÇÃO E O COMBATE: O PAPEL DO ADVOGADO NA MEDIAÇÃO, EM PERSPECTIVA COMPARADA (RIO DE JANEIRO E BUENOS AIRES)
}

\section{BETWEEN COOPERATION AND COMBAT: LAWYERS' ROLE IN MEDIATION, IN COMPARATIVE PERSPECTIVE (RIO DE JANEIRO AND BUENOS AIRES)}

\author{
${ }^{1}$ Bárbara Gomes Lupetti Baptista \\ ${ }^{2}$ Klever Paulo Leal Filpo
}

\section{RESUMO}

Este trabalho resultou de pesquisa empírica, por contraste, no Rio de Janeiro e em Buenos Aires, problematizando diferentes modos de atuação dos advogados na mediação. No Rio essa atuação sofre resistência. Em Buenos Aires é mais ampla e encarada de forma positiva. Há, contudo, um aspecto comum: a expectativa dos mediadores sobre um modo específico de "ser advogado", distinguindo os "bons" daqueles considerados "desqualificados" para esse múnus. Esta valoração está associada a duas categorias: advocacia colaborativa e de combate. Entrevistas e observações evidenciaram que o advogado é fundamental na mediação, desde que coopere para resgatar o entendimento entre as partes.

Palavras-chave: Mediação de conflitos, Advogados, Rio de janeiro, Buenos aires, Pesquisa empírica

\begin{abstract}
This issue resulted from empirical and comparative research, in Rio de Janeiro and Buenos Aires. It discusses different kinds of lawyers' actuation in mediation. In Rio, this actuation suffers resistance. In Buenos Aires, it is broader and viewed in a positive way. There is, however, a common feature: the expectation about a specific way of "being a lawyer". They distinguish "good lawyers" from those considered "inappropriate" for this job. This valuation is associated with two categories: collaborative or combative lawyers. Interviews and observations showed that lawyers are essential if they can cooperate to rescue the understanding between the parties.
\end{abstract}

Keywords: Conflict mediation, Lawyers, Rio de janeiro, Buenos aires, Empirical research

\footnotetext{
${ }^{1}$ Doutora em Direito pela Universidade Gama Filho - UGF, Rio de Janeiro, (Brasil). Professora Permanente da Universidade Veiga de Almeida - UVA, Rio de Janeiro. E-mail: blupetti@globo.com

${ }^{2}$ Doutor em Direito pela Universidade Gama Filho - UGF, Rio de Janeiro, (Brasil). Professor Assistente da Universidade Católica de Petrópolis - UCP, Rio de Janeiro. Faculdade de Direito, Núcleo de Prática Jurídica. E-mail:

klever.filpo@yahoo.com.br
} 


\section{INTRODUÇÃO}

Este artigo é fruto de pesquisa empírica realizada no âmbito do projeto "Estudos empíricos sobre a aplicação de mediação de conflitos pré-processual em Buenos Aires Argentina", contemplado pela chamada MCTI/CNPq/MEC/CAPES nº 22/2014.

Pretende-se problematizar, principalmente, as diferentes formas de trânsito dos advogados nos espaços de mediação de conflitos, no Rio de Janeiro e em Buenos Aires, tentando compreender as representações dos mediadores sobre aqueles profissionais que eles consideram "bons" ou "maus" advogados para a mediação.

No Rio de Janeiro, o trabalho de campo evidenciou certa resistência apriorística e um tanto generalizada à atuação dos advogados nos espaços judiciários em que a mediação é colocada em prática, até então sob a égide da Resolução 125 do CNJ. Em Buenos Aires, parece existir uma dimensão positiva e mais ampliada da atuação dos advogados na mediação que é adotada naquela cidade autônoma como um mecanismo de administração de conflitos, o qual, por força de lei, é obrigatório e anterior ao ajuizamento de demandas cíveis.

Para além dessa aparente diferença, pretendemos, neste paper, chamar atenção para o aspecto comum destacado em ambos os espaços de pesquisa. Trata-se da expectativa dos mediadores em relação a um modo específico de "ser advogado", que, como adiantamos, reflete uma hierarquia valorativa que distingue os "bons advogados" daqueles que os mediadores consideram "desqualificados" para o múnus da mediação.

Em ambos os espaços de pesquisa, esta valoração positiva ou negativa do exercício da advocacia está associada a duas categorias-chave, que foram acionadas por diversos interlocutores: (1) advocacia colaborativa e (2) advocacia de combate. Nos espaços em que a mediação é colocada em prática, para ser considerado um bom advogado, é preciso demonstrar um perfil colaborativo, do modo que será demonstrado neste paper.

A pesquisa de campo foi realizada por meio de entrevistas com mediadores, além da observação de sessões de mediação no Rio e em Buenos Aires. Nos dois espaços, a presença do advogado é considerada, ao menos em tese, fundamental na mediação. Mas somente se a sua atuação seguir certo script, sob pena de transformar o espaço de diálogo da mediação em espaço de combate processual. Circunstância esta que também enuncia significados interessantes e contrastivos entre a administração de conflitos realizada através da mediação, valorizada como um espaço de empoderamento das partes e "pacificação de conflitos", distinto daquele espaço de luta e de combate, reservado, no plano desse discurso, ao processo 
judicial. Este último, no lugar de administrar, poderia acabar acirrando ainda mais os conflitos interpessoais.

O texto está sistematizado de forma a destacar, primeiro, aspectos gerais da implementação da mediação que observamos no Rio de Janeiro e em Buenos Aires. Em seguida, discute o contraste entre os conceitos de advocacia combativa e advocacia colaborativa e, por fim, descreve os dados de trabalho de campo realizado com mediadores, a fim de perceber a distinção valorativa que aparece nas diferentes formas de "ser advogado em mediação". Os resultados do trabalho de campo sugerem conclusões ainda incipientes acerca dos espaços de mediação, da atuação dos atores nesses espaços e até mesmo das expectativas acerca da implementação do instituto, tanto aqui quanto em Buenos Aires.

\section{O CONTEXTO DAS PRÁTICAS DE MEDIAÇÃO NO RIO DE JANEIRO E EM BUENOS AIRES}

A mediação costuma ser definida como um método autocompositivo de resolução de conflitos através do qual as partes em litígio são auxiliadas por um terceiro neutro e imparcial (o mediador) para que elas próprias possam chegar a uma solução adequada para o litígio (BRAGA NETO, 2012). O atributo "autocompositivo" se refere ao protagonismo das partes na definição do que é melhor para si próprias, em vez de entregarem ao juiz o poder de decidir a esse respeito.

Na explicação de Carnelutti (2000, p. 269), “autocomposição é a expressão do poder reconhecido à vontade dos interessados para a tutela dos seus interesses. O fato de que o litígio possa ser composto pelas próprias partes sem intervenção do juiz significa que a lei remete à vontade delas no que concerne à tutela dos interesses recíprocos”.

Nesse contexto de empoderamento das partes, a atuação do mediador assume papel importante, ao mesmo tempo em que se verifica a proporcional redução dos poderes do Juiz e do protagonismo dos advogados. Ambos têm de ceder o lugar de atores privilegiados para as partes, contentando-se com uma atuação mais secundária com a qual não estão, ainda, acostumados, por não ser este o ethos do campo jurídico tradicional.

Segundo uma fala recorrente de nossos interlocutores, em solo argentino, antes da adoção das práticas de mediação, os advogados estavam bem acostumados a uma atuação processual contenciosa, na qual sempre exerceram o papel de porta-vozes das partes, atuando em seu lugar, falando em seu nome, litigando por procuração e, portanto, exercendo uma postura de atores principais, dos quais as partes eram meras coadjuvantes. Hoje, com a 
mediação, a proposta é de que esta posição se inverta, trazendo dificuldades para que os advogados se reconheçam neste lugar, secundário, de colaboração, e não de protagonismo.

A curiosidade que levou a este trabalho foi, portanto, a de direcionar o olhar para o campo empírico, a fim de entender de que modo o papel do advogado interfere no sucesso ou no malogro da mediação, a partir da perspectiva dos próprios mediadores. Em princípio, o contraste com Buenos Aires chamou a atenção. Lá o papel de mediador é exclusivo dos advogados, exigindo-se esta formação como requisito essencial, ao contrário do modelo agora adotado no Brasil, por força de recentes inovações legislativas que serão oportunamente apontadas.

Esta restrição do modelo argentino se chocou com algumas crenças e idealizações muito presentes entre os entusiastas da mediação (por exemplo, WARAT, 2004), sendo uma percepção bastante disseminada no campo o fato de que seria "melhor" para a mediação que a mesma fosse conduzida por atores com formação mais humanística e menos combativa, associando-se, a todo o momento, uma cultura de mediação com uma formação menos belicosa dos advogados. Uma mediadora entrevistada na Argentina, com formação em ciências sociais, nos confidenciou que "os últimos a quem eu entregaria a função de mediador seriam os advogados", denotando que também na Argentina essa opção legislativa deu e continua dando margem a discussões.

No Brasil, o Código de Processo Civil atual permite que qualquer pessoa capacitada em curso específico de formação de mediadores possa funcionar como mediador. De outro lado, a legislação processual exige que as partes compareçam às sessões de mediação acompanhadas de advogado ou de defensor público. Já os mediadores portenhos, dentre outros requisitos, devem comprovar experiência na advocacia, tendo, portanto, formação jurídica. Assim como é cogente a participação dos advogados nas sessões, na qualidade de representantes das partes. Esta é, por sinal, uma exigência inarredável por lá. Algumas sessões de mediação observadas em Buenos Aires começaram atrasadas ou não ocorreram porque os advogados não estavam presentes.

É impossível deixar de registrar que, em Buenos Aires, os mediadores, advogados e partes convivem com a mediação institucionalizada há mais de 20 (vinte) anos. Aqui, no Rio de Janeiro, modelo parecido somente passou a existir há cerca de 06 (seis) anos, por meio de uma Resolução, e não de uma lei federal, que só veio a ser aprovada em 2015, circunstância que precisa ser observada porque, certamente, interfere na forma como as práticas acontecem aqui e lá. 
Com efeito, no Brasil, o grande marco para implementação da mediação foi a Resolução $n^{\circ}$ 125/2010 do Conselho Nacional de Justiça (CNJ), que trouxe as primeiras diretrizes para criação dos Centros de Mediação e a formação dos mediadores. Previamente a essa resolução, havia apenas algumas medidas tímidas, dos próprios Tribunais - como a Resolução nº 19/2009 do Tribunal de Justiça do Estado do Rio de Janeiro (TJRJ) - em que houve uma primeira tentativa de institucionalizar a mediação de conflitos.

Somente no ano de 2015 houve inovações legislativas tratando, especificamente, da mediação. Em março de 2015 foi aprovado o novo Código de Processo Civil (Lei n ${ }^{\circ}$ 13.105/2015), trazendo especial tratamento para a mediação e a conciliação em juízo. Em seu artigo $3^{\circ}, \S 3^{\circ}$, estabelece que todos os operadores do direito devem incentivar o uso de tais métodos. Também em março de 2015 foi aprovada a Lei de Mediação (Lei nº 13.140/2015), um marco legislativo importante que tratou, dentre outros, de regulamentar a profissão do mediador judicial e extrajudicial, destacando, também, as diferenças entre os dois modelos.

Pareceu-nos que o tratamento conferido às práticas de mediação e a sua absorção dentro do sistema é bastante influenciado pelo transcurso do tempo, sendo que aqui ainda estamos travando os primeiros contatos com esse instituto, enquanto lá, em Buenos Aires, podese dizer que já existe uma cultura jurídica incorporando e convivendo com a mediação há mais de duas décadas, circunstância que seguramente repercute nos dados de campo ora apresentados.

\section{ADVOCACIA COLABORATIVA E ADVOCACIA COMBATIVA}

No Brasil, o discurso que exalta uma forma diferenciada de "ser advogado", contrastando com o modelo "tradicional" de advocacia é algo muito recente. Em 2013, a edição X do Prêmio Innovare, que prestigia práticas inovadoras que contribuem para a maior eficiência, bom funcionamento e modernização da Justiça brasileira, contemplou com o primeiro prêmio projeto centrado na adoção de práticas de advocacia colaborativa, destacando-a como uma novidade relevante para o meio jurídico.

A premiação na categoria advocacia prestigiou o projeto "Práticas Colaborativas no Direito de Família", que propunha justamente a difusão da ideia de advocacia colaborativa, importada dos Estados Unidos, com o objetivo de destacar a importância da atuação dos advogados na celebração de acordos entre as partes, antes que a questão chegue ao Judiciário. Após, na edição XII, do ano de 2015, também foi prestigiada essa prática, através do projeto 
“Advocacia Colaborativa - novos padrões de atendimento jurídico empresarial trabalhista em escritórios de advocacia" 1 .

De modo geral, a advocacia colaborativa consiste em um conjunto de práticas que pretendem criar um ambiente de cooperação entre os diferentes atores do processo, em que todos possam buscar uma solução viável. Exige-se, entre os advogados, a constituição de um "termo de não litigância", que marca a forma de atuar, voltada para o consenso e não para o combate. Nos Estados Unidos, a International Academy of Collaborative Professionals (IACP $)^{2}$ promove capacitação em advocacia colaborativa e conta com mais de 5 mil membros espalhados por 24 países.

A advocacia colaborativa está sempre associada, por contraste, à advocacia de combate, porque visa à construção de acordos, renunciando à opção pelo litígio. Segundo diversos estudiosos da mediação de conflitos (v. g. VEZZULLA, 2013; NICÁCIO, 2012) a formação dos advogados está bastante marcada por práticas de litígio e de combate, materializadas no contencioso, que valoriza positivamente uma atuação mais aguerrida desses profissionais na defesa dos interesses dos seus clientes.

Uma das razões que se constitui como premissa para a discussão proposta neste texto, diz respeito ao fato de que o processo judicial brasileiro está marcado pela lógica do contraditório. Conforme registrado em distintos trabalhos empíricos, essa lógica configura obstáculo significativo na construção das formas consensuais de administração de conflitos, notadamente porque provoca nas partes o dever de litigar e, por conseguinte, o dever de discordar, que, incontinenti, resulta em incapacidade de construir pontes de comunicação e diálogos (DUARTE e IORIO FILHO, 2015; KANT DE LIMA, 2011; LUPETTI BAPTISTA, 2008; AMORIM, 2006).

Materializada, portanto, no dever das partes de se contradizerem até o infinito, a lógica do contraditório constrói um mecanismo que transfere para a autoridade judicial (e retira das partes) a possibilidade de eleger uma forma consensual de solução do conflito. Maria Stella de Amorim (2006, p.107-133), partindo de uma visão sociológica, explica que:

[...] a característica essencial dessa lógica, a despeito de sua estrutura aberta, encontra-se na supressão da possibilidade de os participantes alcançarem

\footnotetext{
${ }^{1}$ Desde 2004, o Instituto Innovare dissemina propostas e ações que contribuem para a eficiência, a criatividade, a desburocratização e a agilização dos serviços judiciais. O prêmio é dividido em categorias e busca difundir práticas jurídico-administrativas que possam promover eficiência e celeridade no sistema de Justiça. Os projetos mencionados estão disponíveis na página eletrônica desse Instituto, acesso em 23 mar. 2016.

${ }^{2}$ Informação disponível em: < https://www.collaborativepractice.com/>. Acesso em 23 mar. 2016.
} 
concordância, sejam eles partes do conflito, operadores jurídicos ou doutrinadores, o que sugere ausência de consenso interno ao saber produzido no próprio campo e, no limite, falta de consenso externo, manifesto na distribuição desigual da justiça entre os jurisdicionados pelas mesmas leis que lhes são aplicadas e pelos mesmos tribunais que lhes ministram a prestação jurisdicional. (2006:107-133)

A lógica do contraditório, segundo Kant de Lima (2011, p. 28), se explicita "pela promoção de um dissenso infinito, o qual só se interrompe através de uma autoridade externa às partes, que lhe dá fim e declara uma tese vencedora e a outra, vencida”. Essa lógica, ainda segundo o mesmo autor, seria própria dos modelos judiciários calcados no dissenso, que se distinguem daqueles baseados no consenso.

A lógica do contraditório posiciona-se, assim, de forma antagônica à lógica do consenso. Nesta última, tal como se espera ocorrer no ambiente de práticas consensualizadas, como a mediação, pretende-se promover o protagonismo (ou empoderamento) das partes, para que estas cheguem juntas à solução que melhor lhes interesse. Para que isso ocorra, é necessário que efetivamente acreditem ser este o melhor caminho a seguir. Mas essa pretensão faz muito pouco sentido quando fatores culturais apontam a autoridade judiciária como única capaz de decidir os conflitos, proferindo uma sentença para terminar com o impasse, "declarando uma tese vencedora e a outra, vencida" (KANT DE LIMA, 2011, p. 28).

É nesse sentido que o contraditório, por propor uma relação necessariamente competitiva (conflituosa) acaba sendo um empecilho à construção de consensos e diálogos no processo e dificulta possibilidades cooperativas e uma participação ativa e conjunta das partes na administração dos conflitos.

Duarte e Iorio Filho (2015, p. 36) são muito felizes ao sustentarem que a "lógica do consenso" estrutura procedimentos discursivos decisórios/interpretativos que prestigiam e voltam-se à formação de acordos/consensos, permitindo que se esteja diante "da autoridade do argumento". Em contraposição, a "lógica do contraditório" opera pela (e a partir) da divergência, valendo-se da autoridade, ou seja, o que vale é "o argumento de autoridade". Nessa linha de pensamento, a passagem de uma cultura de litígio para uma perspectiva de consenso reverbera a dicotomia advocacia combativa versus advocacia colaborativa, exigindo do campo, que clama por novas práticas e comportamentos, uma virada de chave a qual depende da adesão dos operadores, sob pena de insucesso e de frustração das expectativas que giram em torno dessa nova perspectiva de administração de conflitos.

Mello e Lupetti Baptista (2011) identificam nesse contraste entre uma "cultura da litigiosidade" e o "anseio por pacificação social" um dos obstáculos à efetiva implementação 
da mediação como forma de administração de conflitos pelos Tribunais Brasileiros. Por outro lado, como apontado por Filpo (2014), a mediação se apresenta como um corpo estranho no contexto das instituições judiciárias, eis que marcada por uma lógica do consenso e da igualdade entre todos os atores. Muito diferente do que ocorre na praxis judiciária, onde há uma disputa somente encerrada pela intervenção da autoridade do juiz, cuja vontade se sobrepõe à das partes.

$\mathrm{Na}$ tentativa de estimular mudanças nesse cenário, hoje, o Novo Código de Processo Civil, traz uma promessa de conformação do sistema processual introduzindo o contraditório cooperativo como princípio processual. O diálogo paritário entre todos os atores do processo passa a ser o fundamento do desenvolvimento processual (COÊLHO, 2011, p. 46). Cassio Scarpinella Bueno (2015, p. 85) também promove o discurso da cooperação e menciona que se trata de um novo "modelo de tutela jurisdicional", que desloca para as partes a participação na construção da decisão judicial.

Talvez, esta seja a virada de chave acima mencionada, que poderá permitir a construção de pontes, em vez de afastamentos, a consolidar uma atuação mais colaborativa dos advogados brasileiros que, até hoje, sempre se destacaram por um papel mais combativo, litigioso e bélico. Nessa linha, voltando à parte inicial destacada neste tópico, a ideologia da advocacia colaborativa "cai como uma luva" à prática da mediação, que associa a ideia de "ser um bom advogado" à circunstância de ser "colaborativo", deixando de lado a tradição combativa que, tradicionalmente, poderia ser considerada traço característico da profissão.

\section{OS DADOS DE CAMPO: ENTRE A COLABORAÇÃO E O COMBATE}

$\mathrm{Na}$ pesquisa de campo verificamos que, tanto aqui quanto em Buenos Aires, não é propriamente o fato de existir um advogado na mediação que obstaculiza o sucesso das técnicas que lhe são próprias, mas a forma como este advogado se comporta durante as sessões. Ou seja, dependendo de como o advogado atua e de sua postura na sessão de mediação, o instituto funciona ou não funciona. Como nos disseram alguns interlocutores fluminenses e portenhos: "a presença do advogado é fundamental na mediação, desde que a sua atuação seja colaborativa".

A diferença entre o Brasil e a Argentina, neste particular, pode ser resultado do tempo em que a mediação já existe na cultura jurídica e social. Contrastando os discursos dos mediadores cariocas ouvidos no TJRJ com os discursos dos mediadores portenhos com quem conversamos, tivemos a percepção de que, em Buenos Aires, existiriam mais advogados 
considerados colaborativos, acostumados com a mediação, do que combativos. Ou, de certo modo, pode ter ocorrido uma natural distribuição desses quadros entre aqueles que preferem trabalhar com a mediação e os que não aderiram a essa prática. Isso é possível porque, embora a mediação seja obrigatória em Buenos Aires, a parte não é obrigada a celebrar acordo. Assim, para chegar à via judicial, basta informar na primeira sessão de mediação que não existe o desejo de mediar.

Nos espaços de mediação, segundo algumas mediadoras portenhas, havia, no início, uma postura muito litigante dos advogados, o que "prejudicava" as mediações. Hoje, cada vez menos os advogados "de litígio" fazem mediações, que ficam mais resguardadas para advogados que “compraram a ideia do consenso". Aqui no Brasil, como o instituto é novo, a resistência ainda é bastante grande e as tensões, como veremos, mais acirradas.

\subsection{O Combate: As Tensões no Rio de Janeiro}

Nossa experiência empírica no Rio de Janeiro compreendeu observações e entrevistas realizadas no TJRJ entre os anos de 2010 e 2014. Alguns dos dados obtidos são aqui associados aos resultados de outras pesquisas empíricas no campo das ciências sociais realizadas entre 2013 e 2015. Nesse recorte, percebemos que há uma grande tensão entre os magistrados, mediadores e os advogados, no tocante à introdução da mediação de conflitos no ambiente forense. Estes últimos são enxergados, por muitos de nossos interlocutores, como atores bélicos, que dificultam a solução consensualizada do conflito. Segundo uma mediadora entrevistada por Veras (2015, p. 135), os advogados não gostam da mediação porque "perdem a potência", isto é, percebem que nas sessões de mediação não são eles os principais protagonistas e podem estranhar isso.

É certo que durante a pesquisa de campo no TJRJ, os mediadores e juízes sempre afirmaram que a Ordem dos Advogados do Brasil e os próprios advogados não estão excluídos da mediação. Entretanto, na prática, percebemos que paira certo estigma sobre os advogados, nas sessões de mediação.

Veras (2015), Filpo (2014) e Rangel (2013) descrevem muito bem as tensões entre mediadores e advogados em seus trabalhos empíricos. Na tese de Veras (2015, p. 134), ela chega a narrar a "ameaça" que um constitui ao outro e descreve falas em que, por exemplo, mediadores afirmam que "achávamos um saco a presença do advogado". Como não havia, até 2015, legislação sobre o tema, assegurando a presença dos advogados nas sessões de mediação (como agora ocorre em vista do texto do Novo CPC), a participação dos advogados 
nessas sessões costumava causar muita polêmica e ruídos. A Resolução no 29/2009 do TJRJ informava que a participação dos advogados na mediação deveria ser incentivada, evitando usar expressões que pudessem tornar essa presença obrigatória.

$\mathrm{Na}$ Comarca da Capital, quando realizamos a pesquisa de campo, havia na sala de espera do Centro de Mediação um aviso com o seguinte teor: "Senhores Advogados. Aviso: é facultado aos senhores a presença na sala de mediação, observando-se o desejo das partes”. Acreditamos que se tratava de uma forma sutil de mantê-los afastados. Assistimos a algumas sessões de mediação que prescindiram da presença do advogado ou do defensor público, especialmente em se tratando de mediações pré-processuais. Em uma delas, a mediadora não se conteve e declarou: "como é melhor quando o advogado não está...".

Veras (2015, p. 135) menciona que uma mediadora com quem conversou disse que no início tinha de "sensibilizar" os advogados e ficava ensinando técnica de atuação colaborativa para permitir que a mediação fluísse. Muitas vezes, percebia a presença desses profissionais como um empecilho.

Uma mediadora certa vez comentou que os advogados são muito "agressivos" quando estão acostumados com o processo e não conseguem atuar de forma cooperativa na mediação, porque "não foram treinados para o diálogo". Outra, ressaltou: "a presença do advogado é fundamental. Mas, eles têm que estar preparados para agir de forma colaborativa. Caso contrário, prejudica a sessão".

Importante dizer também que, igualmente, por parte dos advogados, tampouco existe euforia quanto ao uso desse método. Os advogados entrevistados - aqueles militantes demonstraram muito pouco interesse pela mediação. Muitos deles não sabiam nem mesmo que existia tal instituto, antes que se tornasse uma etapa processual obrigatória em vista do Novo CPC. Veras (2015) também menciona em sua tese o desinteresse dos advogados nessa forma diferenciada de administração de conflitos. Um dos advogados entrevistados pela autora foi taxativo ao asseverar que "este centro de mediação não é uma coisa boa para os advogados" (2015, p. 132).

Outra preocupação constante dos advogados diz respeito ao tempo demandado para que as mediações possam acontecer de modo satisfatório. O tratamento de um caso nos centros de mediação é sempre demorado. São necessários vários encontros, chamados sessões (ou audiências, no Novo CPC) e muita conversa para que as partes possam chegar a um entendimento, o que nem sempre acontece. Quando não há acordo, o processo retoma o seu curso normal e, nesse caso, todo o tempo despendido na mediação é "perdido". Exceto quando se constata uma melhora na comunicação, a despeito da não formalização do ajuste. 
Os mediadores consideram que a boa mediação prescinde da formalização de um acordo, sendo suficiente o restabelecimento do diálogo entre as partes. Já os advogados, mais pragmáticos, parecem considerar que a mediação sem acordo é antiprodutiva. Um advogado nos disse claramente: "Que perda de tempo! Ficar aqui mais de uma hora para ouvir a parte reclamar de um extravio de bagagem que não deu em nada...". "Não dar em nada", na sua fala, significava não atingir um acordo que pudesse extinguir o processo.

Todas essas falas, que se apresentaram de forma recorrente durante a pesquisa de campo, foram por nós interpretadas da seguinte maneira: o fato de a mediação ser um mecanismo de administração de conflitos muito recente entre nós, sobretudo quando inserida nos espaços judiciários e dentro dos processos, é capaz de gerar muitas tensões entre os diferentes atores do campo jurídico, que ainda estão em busca de uma melhor delimitação dos seus espaços e das suas práticas. No Brasil, ao que nos pareceu, o caminho que será capaz de conduzir do modelo de combate ao modelo de cooperação ainda precisa ser bastante sedimentado.

\subsection{Um Caminho para a Cooperação: A Experiência Portenha}

O trabalho de campo a que se refere este item foi realizado em Buenos Aires por nossa equipe de pesquisadores, utilizando recursos disponibilizados pelo CNPq-Brasil, em alguns períodos distribuídos durante o ano de 2015. Nosso foco foram instituições públicas que prestam serviços de mediação às pessoas que não têm condições de pagar por esse serviço, especialmente a Direção Nacional de Mediação e a Universidade de Buenos Aires.

Na Argentina, a primeira lei de Mediação foi publicada em 1996 (Ley no 24.573) e estabelecia a mediação pré-judicial obrigatória para as causas cíveis, como regra geral. Isto é, em determinados casos estabelecidos na legislação, as partes deveriam primeiramente procurar um mediador e realizar pelo menos uma sessão de mediação. Caso essa tentativa fosse infrutífera, aí sim as partes poderiam ingressar no Judiciário para solucionar o conflito. A ata de mediação constituía documento indispensável para ser apresentado junto da petição inicial. Por ser um novo método de resolução de conflitos, a lei tinha um prazo de vigência, a título de experimentação. Assim, em vista de resultados positivos, foi publicada nova Lei de Mediação (Ley n 26.589/2010), vigente até o momento, apresentando poucas diferenças em relação ao diploma anterior.

Vale dizer que, em Buenos Aires, identificamos outras modalidades de mediação, para além desta que se encontra regulada pela Ley 26.589. Contudo, neste artigo, para efeito de 
delimitação, é esta modalidade, prejudicial e obrigatória, o que nos interessa e que foi objeto de nossas observações.

Esse trabalho de campo nos permitiu identificar uma relação mais harmoniosa entre advogados e mediadores do que aquela que havíamos observado no Rio de Janeiro. Não se quer dizer com isso que não existam tensões. Elas ocorrem. Mas os mediadores entrevistados, ao menos no seu discurso, entendem a figura do advogado colaborativo como essencial para o sucesso da mediação e muitos interlocutores disseram que existem advogados muito "bem preparados" para a mediação.

Nossos interlocutores nos contaram que, quando do surgimento da primeira lei de mediação, havia muita desconfiança sobre todo o sistema de mediação, por ser um novo instrumento de resolução de conflitos, e que toda aquela desconfiança recaía, em última análise, sobre os mediadores e o seu trabalho. Uma das razões dessa desconfiança, segundo nossos interlocutores, teve como origem a falta de capacitação dos mediadores, que hoje já estaria superada, conferindo maior legitimidade à mediação.

Outro aspecto foi o investimento na divulgação desse método, que fez com que se tornasse muito comum e internalizado na cultura portenha. Ao menos segundo as mediadoras que entrevistamos. Segue um dos depoimentos mais significativos nesse sentido (em tradução livre):

\begin{abstract}
Quando o sistema de mediação começou, o sistema prejudicial obrigatório, houve uma grande resistência dos advogados. Porque o advogado sabia que o mediador era um advogado como ele, que tinha apenas uma escassa formação, que era o que exigia o Ministério da Justiça. Naquela época, o Ministério da Justiça exigia uma capacitação, mas não fazia exames e tampouco requeria, como requer hoje em dia, que os mediadores façam a capacitação permanente ou contínua, como se chama. Então, o advogado, que ademais sabia que muitos dos advogados-mediadores eram advogados que "escapavam" o exercício tradicional da profissão, não eram pessoas com a convicção de desenvolver um novo modelo de resolução de conflitos, mas sim, muitos deles eram pessoas que não gostavam do exercício profissional; que achavam que a mediação era um caminho um pouco menos difícil, talvez...coisa que não é...bem, os advogados se sentavam em uma mesa de mediação, com um mediador pouco expert, que não sabia transmitir, nem conduzir um processo e isso gerou muita resistência [...] então, nesse quadro, o mediador estava muito exposto, tinha que aprender a conduzir um processo; e, ademais, tinha que dar resposta aos advogados que se sentavam à mesa de mediação já com um litígio. Assim, muitos mediadores foram abandonando o ofício. Paralelamente, o Ministério da Justiça começou a estabelecer mais requisitos na capacitação: se estabeleceu em determinado momento um exame de idoneidade etc...hoje o processo é mais sério e mais legítimo. (mediadora portenha)
\end{abstract}

Ao contrário disso, tendo por base sua experiência atual, quando já decorridas duas décadas desde a primeira lei de mediação obrigatória, as mediadoras que ouvimos no campo 
afirmaram que a participação dos advogados na sessão de mediação, na maior parte das vezes, é benéfica para todos. E afirmaram isso, de forma recorrente, pelo fato de que o advogado da parte - e somente ele - pode orientar seu cliente sobre o melhor acordo. Sua intervenção é encarada como uma orientação jurídica válida, que confere segurança e, não raro, fornece as condições para que o acordo seja celebrado.

Isto porque os mediadores não podem orientar as partes sobre a realização do acordo. Uma Mediadora nos contou (em tradução livre):

MEDIADORA: Hoje eu acho que seria muito difícil mediar sem advogados.

ENTREVISTADORES: Por quê?

MEDIADORA: Porque em determinadas questões [...] é que hoje temos muitos advogados formados em negociação. Nós formamos na Faculdade...não são mediadores. Os meninos não se formam como mediadores. Mas nós os formamos como advogados que acompanham a sessão de mediação. Como advogados que têm que saber como preparar o seu cliente para negociar melhor. Então, esses advogados que vêm à mediação, são os que eu preciso, porque em nosso modelo de mediação, nós não podemos dizer o Direito, não podemos dizer a lei. Por isso, eu preciso fazer um trabalho com os advogados que acompanham as partes, para que ajudem a instruir seu cliente sobre quais são as opções, quais são as alternativas. O advogado tem o saber jurídico para instruir seu cliente. Então, eu necessito desse advogado colaborador na mesa de mediação. Eu não posso assessorar a parte, o outro. Obviamente, não posso assessorálo desempenhando a função de mediadora. Então, eu necessito de advogados que sejam formados em negociação, pelo menos. Que eles conheçam qual o papel que têm...de ajudar na mediação...de instruir...

É certo que entrevistamos muitos mediadores e que, obviamente, os seus discursos estão perpassados por uma lógica de militância e de idealização, o que ficou bastante perceptível em vários momentos. Por exemplo, quando percebemos que o público em geral, diferente do que nos fora informado, está muito familiarizado com a mediação trabalhista, que nos pareceu bastante disseminada por lá, mas não com a mediação cível ou de família, por exemplo.

Ainda assim, uma advogada militante nos disse que é uma entusiasta da mediação, porque o sistema está "colapsado" e, segundo ela, a mediação é um caminho eficaz e mais rápido, alternativo à via judiciária convencional. Segundo ela, é possível identificar advogados pouco preparados para atuar com a lógica de mediação, que exige uma postura menos combativa, mas a maioria dos colegas atua em uma proposta mais cooperativa.

De fato, assistimos a uma sessão de mediação, certa vez, que discutia uma ação indenizatória contra uma seguradora em que a advogada da seguradora era bastante combativa, questionadora e apegada a aspectos processuais formais. $\mathrm{O}$ acordo não se realizou 
e, ao final, puxamos assunto com a mediadora, acerca de suas impressões pessoais sobre a audiência, e ela disse: "viu que diferença da audiência anterior? A diferença é a postura do advogado. Faz toda diferença isso. Esta advogada era muito de 'litígio'. Aqui, não funciona assim...".

Do mesmo modo, entrevistamos mediadoras que disseram que nos espaços em que se faz mediação pública (ou seja, gratuita, serviço prestado por algumas universidades e órgãos públicos, especialmente a Universidade de Buenos Aires), os próprios mediadores têm uma postura mais de "litígio". São mediadores, mas têm um espírito mais de advogados e, portanto, também a mediação fica diferente, dependendo da formação do mediador.

Percebemos que existia uma espécie de hierarquização entre mediadores "puros", colaborativos, porque só fazem mediação, e outros, "impuros", que desempenham ora o papel de advogados, ora de mediadores. Essa dicotomia apareceu, por exemplo, na seguinte fala (traduzida de forma livre):

Os advogados que temem a mediação devem ser incluídos. O que eu trato de fazer é trazer os advogados ao processo, de incluí-los; e que eles estejam trabalhando para que isto funcione. Se não os incluímos, nós perdemos.

Com efeito, essa ideia de "aliança", de "trazer para o nosso lado", de "convencer sobre os méritos da mediação" para que o projeto dê certo, apareceu com recorrência no campo portenho. Algo pouco perceptível no Rio de Janeiro, onde os advogados foram vistos, por muitos, como obstáculo à mediação, devendo esta ser manejada apenas por profissionais capacitados a operá-la, consubstanciando um determinado nicho profissional bem delimitado, do qual os advogados estariam, a princípio, excluídos - na nossa percepção.

Outro aspecto que apareceu nas entrevistas foi a relação entre o advogado e a parte por ele assistida, assim como a necessidade de se desenvolver um aprendizado para "sair do lugar de poder" e passar a palavra à parte. Assim como aqui, lá, em Buenos Aires, as mediadoras narraram, e nós também observamos, sessões de mediação que não fluíam da forma esperada porque o advogado atuava na mediação como se estivesse em juízo e demonstrava muita dificuldade em se deslocar do seu lugar de fala. Tal circunstância é compreensível já que lá, como aqui, a parte se faz representar em juízo por meio de um advogado legalmente habilitado.

Uma mediadora nos informou que, na mediação (em tradução livre): 
As partes é que são protagonistas, digamos, são partes interessadas, etc. É verdade que muito advogados também tomam a palavra. Então, é função do mediador perguntar e aí trazer a parte, sem deslegitimar o advogado, [não permitindo] que o advogado se sinta cômodo. Mas o mediador, muitas vezes o que pode fazer é perguntar às partes diretamente, pois elas são mais pontuais e começam a falar.

Por contraste, percebe-se, principalmente, que a prática de mediação portenha tem levado a que os atores busquem construir uma relação menos conflituosa entre si. O tempo ao longo do qual esse método já vem sendo empregado, as características desse modelo que impõe o uso da mediação como meio preferencial de administração de diversificados conflitos cíveis, e a presença dos advogados nas sessões (quer como mediadores, quer como advogados das partes), parecem ter contribuído para que, a despeito de todas as tensões verificadas, os ânimos se amainassem e os perfis se amoldassem à realidade mais cooperativa que se pretende necessária ao funcionamento da mediação. Circunstância esta que ainda parece um pouco distante no Rio de Janeiro, onde as tensões entre os diferentes papéis apresentam-se de forma mais evidente.

\section{CONCLUSÃO: REFLEXÕES E CONTRASTES}

A proposta deste trabalho foi problematizar diferentes formas de trânsito dos advogados nos espaços de mediação de conflitos, no Rio de Janeiro e em Buenos Aires, tentando compreender as representações dos mediadores sobre aqueles profissionais que eles consideram "bons" ou "maus" advogados para a mediação. Essas reflexões tiveram ensejo por meio do contraste entre experiências de campo no Tribunal de Justiça do Rio de Janeiro e instituições públicas que prestam serviços de mediação de conflitos pré-processual e obrigatória na cidade autônoma de Buenos Aires, Argentina.

Percebeu-se que, tanto aqui como lá, os mediadores pretendem estimular, nos espaços em que a mediação é posta em prática, um ambiente favorável ao consenso e à recuperação da comunicação entre as partes. Nessa medida, a expectativa dos mediadores é de que os advogados possam contribuir para o estabelecimento dessas condições, sendo repelidos quando não apresentam um perfil colaborativo. Quando isso ocorre, são identificados como "maus" advogados para a mediação.

Por outro lado, o discurso institucional, e também aquele presente nos livros que tratam de fomentar uma cultura de mediação, procuram convencer quanto à conveniência de preparar os juristas para o consenso. Advogados com esse perfil seriam considerados cooperativos e, por isso, aptos para atuarem nos espaços de mediação: seriam os "bons" 
advogados. É nessa mesma esteira que surgem as propostas de modificação dos currículos das faculdades de direito para que o perfil de seus egressos possa incorporar essa habilidade específica, preparando-os para operarem também a mediação, ao lado da formação convencional para o processo contencioso.

Esse contraste entre a postura cooperativa e a postura combativa nos remete à dicotomia entre a própria essência da mediação e o processo judicial. A proposta da mediação pretende romper com toda uma lógica adversarial até aqui soberana e onipresente, fazendo sempre a exclusão ou, no mínimo, a desqualificação da via processual convencional (judiciária). O discurso predominante, no momento, é de que a mediação é boa (assim como são considerados bons os advogados que se dedicam à mediação), e o processo judicial é ruim (assim como os advogados que preferem a via judicial são rotulados de maus advogados). Por isso mesmo, pensar o papel desempenhado pelos advogados nesse contexto nos ajuda a entender o próprio lugar da mediação nesse cenário mais amplo de administração de conflitos, pelo Judiciário ou fora dele.

Na mediação são valorizados a autonomia e o protagonismo das pessoas envolvidas diretamente no conflito (os mediandos), tratando-se de um procedimento informal, que pode variar bastante de um caso para o outro, propenso até mesmo a soluções criativas. Nesse método, a priori, as partes devem decidir o que é melhor para si. Por outro lado, no processo judicial convencional os principais protagonistas são os profissionais com competência jurídica, isto é, o juiz, o promotor, os advogados e defensores, mediante procedimentos um tanto formais e controlados no tempo. O processo de comunicação, em juízo, é geralmente restrito à fala desses profissionais e às manifestações escritas, por meio de petições, ao menos na tradição jurídica brasileira.

Assim, pareceu-nos que os advogados são considerados cooperativos quando se permitem abrir mão do seu modo de atuação tradicional, para permitir que os mediandos e os mediadores possam exercitar, nos espaços de mediação, a sua fala, empregando as técnicas de mediação para restabelecer a comunicação rompida entre as partes. Trata-se, no caso, de um diálogo humano e realizado sem intermediários, exigindo que os advogados se desloquem de seu local tradicional de fala, em que buscam sustentar uma tese de conteúdo jurídico, para, às vezes, comportarem-se mesmo como meros expectadores.

Contudo, como esse deslocamento é difícil, as tensões entre advogados e mediadores pareceu ser algo recorrente, tanto no Brasil (de forma mais aguda) como na Argentina (de maneira mais branda). São essas tensões que parecem justificar o desconforto dos mediadores no tocante à presença dos advogados nas sessões. No Brasil, houve mediadores que se 
mostravam aliviados quando (antes da vigência do Novo CPC) a parte comparecia, eventualmente, sozinha para a sessão, isto é, desacompanhada do seu representante legal.

No momento, tanto no Brasil como na Argentina, nas sessões de mediação consideradas neste paper - isto é, nas audiências de mediação previstas no Novo CPC brasileiro e na mediação prejudicial obrigatória em Buenos Aires - a presença do advogado é obrigatória. Mas isso não significa que as tensões a que nos referimos no parágrafo anterior tenham desaparecido. Elas tendem a ser menos recorrentes na medida em que os profissionais se acostumam com as características próprias da mediação. Ao menos é isso o que sugere a experiência portenha com que mantivemos contato no trabalho de campo.

Também chamou a atenção do fato de que, em Buenos Aires, os mediadores com quem conversamos alertaram para a existência de uma categoria específica de advogados "de mediação". Não se trata de um instituto jurídico e não encontra previsão legal, já que o advogado portenho pode atuar de forma ampla, em qualquer área, em mediação ou em juízo.

É que o tempo de experiência dos portenhos no emprego da mediação parece ter propiciado certas acomodações. Assim, os advogados de perfil mais belicoso, ou que avaliam ser necessário submeter o caso à apreciação judicial, simplesmente orientam os seus clientes a rejeitarem a via da mediação logo na primeira sessão, o que lhes confere acesso rápido à via judicial convencional, onde poderão atuar como advogados propriamente ditos, exercendo o seu múnus da forma tradicional. Ao agirem dessa forma são considerados mais belicosos, mais “de juízo". Em sentido contrário, os advogados "de mediação", nos quais os mediadores identificam um perfil mais cooperativo, transitam bem e tornam-se presença mais frequente nos espaços de mediação, sendo reconhecidos, no campo, por essa característica.

De modo geral, no discurso de nossos interlocutores portenhos, os advogados foram retratados como "aliados" na efetivação dessa forma de gestão de conflitos - quando não protagonizando papel de destaque, como mediadores - enquanto no Brasil a resistência pareceu ser bastante intensa.

No Rio de Janeiro, os advogados foram muitas vezes enxergados, por nossos interlocutores no campo, como uma "ameaça" à cultura da mediação, cuja presença haveria de ser evitada a todo custo, e apenas tolerada quando inevitável. É possível - e talvez imperativo - que esse cenário se modifique com o tempo e que esse conflito latente seja, ele próprio, objeto de acomodações, assim como ocorreu na experiência portenha. Se a cultura da mediação depende de uma postura cooperativa, que ela seja inaugurada pelos profissionais a quem compete colocá-la em prática, sejam advogados, juízes, promotores, defensores, ou os próprios mediadores. 


\section{REFERÊECIAS}

AMORIM, Maria Stella de. Juizados Especiais na Região Metropolitana do Rio de Janeiro. Revista da Seção Judiciária do Rio de Janeiro, n. 17, 2006, p. 107-133.

BRAGA NETO, Adolfo. Mediação de Conflitos: Conceito e Técnicas. In: LORENCINI, Marco Antônio Garcia Lopes; SALLES, Carlos Alberto de; SILVA, Paulo Eduardo Alves da (Coord.). Negociação, Mediação e Arbitragem: Curso básico para programas de graduação em Direito.Rio de Janeiro: Forense, 2012.pp. 103-125.

BUENO, Cassio Scarpinella. Manual de Direito Processual Civil. Volume Único. São Paulo: Saraiva, 2015.

CARAM, Maria Elena; EILBAUM, Diana Teresa; RISOLÍA, Matilde. Mediación - Diseño de una Práctica. Buenos Aires: Librería Histórica, 2006.

CARNELUTTI, Francesco. Sistema de Direito Processual Civil. Vol. I. Tradução Hiltomar Martins Oliveira. 1 ed. São Paulo: Classic Book, 2000.

COÊLHO, Marcus Vinícius Furtado. O contraditório cooperativo no novo Código de Processo Civil. Revista de Informação Legislativa. Brasília ano 48 n. 190 abr./jun. 2011, p. 45-58.

DUARTE, Fernanda; IORIO FILHO, Rafael Mario. A lógica do contraditório: ainda somos medievais. In: CONPEDI/UFS; Gustavo Silveira Siqueira; Antonio Carlos Wolkmer; Zélia Luiza Pierdoná. (Org.). História do direito. Florianópolis: CONPEDI, 2015, p. 1-23.

FILPO, Klever Paulo Leal. Dilemas da Mediação de Conflitos no Tribunal de Justiça do Estado do Rio de Janeiro. 2014. Tese (Doutorado).Programa de Pós-Graduação em Direito da Universidade Gama Filho, Rio de Janeiro.

KANT DE LIMA, Roberto. Sensibilidades jurídicas, saber e poder: bases culturais de alguns aspectos do direito brasileiro em uma perspectiva comparada. Anuário Antropológico, v. 2, p. 25-51, 2011.

LUPETTI BAPTISTA, Bárbara Gomes. Os Rituais Judiciários e o Princípio da Oralidade: construção da verdade no processo civil brasileiro. Porto Alegre: Sergio Antonio Fabris Editor, 2008.

MARQUES, Giselle Picorelli Yacoub. O Judiciário transforma isto numa sentença: as abordagens dos conflitos familiares e as práticas autocompositivas nas regiões de Santarém e Oriximiná. 2016. Tese (Doutorado). Programa de Pós-Graduação em Sociologia e Direito da Universidade Federal Fluminense, Niterói.

MELLO, Kátia Sento Sé; LUPETTI BAPTISTA, Bárbara Gomes. Mediação e conciliação no judiciário: dilemas e significados. Dilemas: Revista de Estudos de Conflito e Controle Social, 2011, v. 4, pp. 97-122.

NICÁCIO, Camila Silva. A Mediação Frente à Reconfiguração do Ensino e da Prática do Direito: Desafios e Impasses à Socialização Jurídica. In: BENTES, Hilda Helena Soares; 
NUNES, Valter Eduardo Bonanni. Jurisdição e Consenso: um estudo interdisciplinar de base empírica sobre Política Nacional de Tratamento Adequado dos Conflitos no âmbito do Poder Judiciário. 2015. Dissertação (Mestrado). Programa de Pós-Graduação em Sociologia e Direito da Universidade Federal Fluminense, Niterói.

RANGEL, Victor Cesar Torres de Mello. "Nem tudo é Mediável". A Invisibilidade dos Conflitos Religiosos e as Formas de Administração de Conflitos (Mediação e Conciliação) no Rio de Janeiro. Dissertação de Mestrado defendida no Programa de Pósgraduação em Antropologia da Universidade Federal Fluminense. Niterói. 2013.

TRIBUNAL DE JUSTIÇA DO ESTADO DO RIO DEJANEIRO. Atos Normativos atinentes à Mediação de Conflitos. Disponível em <www.tj.rj.jus.br>. Acesso em 10 ago. 2014.

VERAS, Cristiana Vianna. Um estranho na orquestra, um ruído na música: a apropriação da mediação pelo Poder Judiciário a partir de uma experiência no CEJUSC do TJRJ. 2015. Tese (Doutorado). Programa de Pós-Graduação em Sociologia e Direito da Universidade Federal Fluminense, Niterói.

VEZZULLA, Juan Carlos. A mediação para uma análise da abordagem dos conflitos à luz dos direitos humanos, o acesso à justiça e o respeito à dignidade humana. In: SILVA, Luciana Aboim Machado Gonçalves da (Org.). Mediação de Conflitos. São Paulo: Atlas, 2013, pp. 63-93.

WARAT, Luis Alberto. Surfando na pororoca: o ofício do mediador. Florianópolis: Fundação Boiteux, 2004. 